\title{
Republic of Armenia: Poverty Reduction Strategy Paper Progress Report- Joint Staff Advisory Note
}

The attached Joint Staff Advisory Note (JSAN) of the Poverty Reduction Strategy Paper Annual Progress Report for the Republic of Armenia, prepared jointly by the staffs of the World Bank and the IMF, was distributed with the member country's Poverty Reduction Strategy Paper Annual Progress Report to the Executive Boards of the two institutions. The objective of the JSAN is to provide focused, frank, and constructive feedback to the country on progress in implementing its Poverty Reduction Strategy (PRS).

To assist the IMF in evaluating the publication policy, reader comments are invited and may be sent by e-mail to publicationpolicy@imf.org.

Copies of this report are available to the public from

International Monetary Fund • Publication Services

$70019^{\text {th }}$ Street, N.W. • Washington, D.C. 20431

Telephone: (202) 623-7430 • Telefax: (202) 623-7201

E-mail: publications@imf.org • Internet: http://www.imf.org

\section{International Monetary Fund} Washington, D.C. 



\title{
INTERNATIONAL DEVELOPMENT ASSOCIATION
}

AND

\author{
INTERNATIONAL MONETARY FUND
}

REPUBLIC OF ARMENIA

\section{Poverty Reduction Strategy Paper-Second Progress Report Joint Staff Advisory Note}

\author{
Prepared by the Staffs of the International Development Association (IDA) \\ and the International Monetary Fund (IMF) \\ Approved by Shigeo Katsu (IDA) \\ and David Owen and Adnan Mazarei (IMF)
}

August 3, 2006

\section{INTRODUCTION}

1. The Armenia Poverty Reduction Strategy Paper (PRSP) was presented to the Boards of IDA and the IMF in November 2003 and focused on the government's commitment to equitable growth and sustained poverty reduction. The Executive Boards and the staffs of IDA and the IMF considered the PRSP to be a significant achievement. In January 2004, the government approved a PRSP Implementation Action Plan, in close consultation with various stakeholders. The authorities prepared a first PRSP Progress Report, which was presented to IDA and the IMF in April 2005. The second PRSP Progress Report completed in June 2006 provides further results of PRSP implementation during the 2004-05 period. A full PRSP Update is planned for early 2007. This Joint Staff Advisory Note (JSAN) discusses PRSP implementation to date, reports on progress in addressing issues raised in the previous JSAN, and provides the staffs' advice on key priorities for strengthening the PRSP process further.

2. Overall, the second PRSP Progress Report provides continuing strong evidence of rapid economic growth, a notable reduction in poverty, and a number of other accomplishments, particularly in fiscal policy and social service delivery. The Progress Report also indicates that progress has been made on many issues raised in the previous JSAN, including on improved monitoring and evaluation, participation, and aligning the budget process with the PRSP. At the same time, continued efforts are needed in three key areas: (i) reforming tax and customs administrations; (ii) deepening competition in key services as well as financial intermediation; and (iii) carrying through on education, health, and pension reforms, although progress continues to be made in these areas. 


\section{Poverty Diagnostic}

3. The Second Progress Report continues to present a high quality and updated poverty diagnostic for Armenia. The staffs commend the government for a detailed poverty assessment and the reduction in overall poverty from around 50 percent in 2000-01 to 39 percent in 2004, including a notable reduction in rural poverty, below the level targeted in the PRSP. Extreme poverty fell from 16 percent in 2001 to 7.2 percent in 2004 . Income inequality also fell during this period, as measured by a reduction in the Gini coefficient from 0.535 in 2001 to 0.387 in 2004 . The Progress Report credits this faster-than-anticipated progress to double-digit economic growth, the increase of labor income, private transfers from abroad, and the increase in social transfers through a well-targeted family poverty benefits program. The Progress Report measures poverty using the same methodology used to plan the PRSP targets. However, it also provides a new baseline for 2004 using an improved methodology. ${ }^{1}$ The government is planning to use this adjusted poverty measurement methodology in the coming PRSP Update.

\section{Based on the Progress Report's findings, the staffs recommend a deepening of} analytical work on poverty, particularly as regards poverty in secondary towns. The Progress Report finds that in 2004 the reduction in poverty was driven by a decline in rural poverty, and, to a lesser extent, of poverty in non-Yerevan urban areas. However, the level of poverty in these areas remains high. Also, some groups such as families with many children face a higher poverty risk. The government has also taken a good first step in analyzing labor markets within the separately published social snapshot. The Progress Report therefore appropriately places continued emphasis on the poorer regions and improvements in reducing the poverty risk of vulnerable groups. The staffs continue to suggest (as in the last JSAN) that further analysis be done on selected topics such as: (i) the structure of poverty in secondary towns, (ii) a qualitative and quantitative assessment of the social and economic situation of population groups experiencing high poverty risk, (iii) income inequality, and (iv) labor market dynamics and job creation.

\section{Priority Areas for Public Actions}

\section{A. Macroeconomic Framework and Sustainable Growth}

\section{Economic performance remains strong, with double-digit growth and low} inflation in recent years. Real GDP growth was in the double-digits in 2002-05 (in line with the PRGF targets) compared with the PRSP target of average growth of 6 percent per year; it has also exceeded 10 percent in the first half of 2006. Economic growth has been driven by a boom in agriculture and continued construction activities. Average inflation was 7 percent in 2004, and less than 1 percent in 2005. The 12-month inflation rate was about 2.7 percent in June 2006. External debt indicators have further improved, with the present

\footnotetext{
${ }^{1}$ The new 2004 baseline indicates a poverty level of 34.6 percent, and extreme poverty at 6.4 percent.
} 
value of debt to GDP ratio declining from 28.4 percent in 2002 to 20.6 percent in 2004 and to14.3 percent in 2005. Nevertheless, the authorities are encouraged to remain vigilant to major sources of macroeconomic vulnerability (including energy price increases) and to continue to pursue prudent fiscal and monetary policies. They are also encouraged to include a forward-looking macroeconomic framework in the Progress Report, consistent with the medium-term fiscal framework outlined in the budget section of the report. Against the backdrop of strong remittance inflows as well as a tighter monetary policy stance during the second half of 2004, the exchange rate of the national currency (dram) appreciated against the U.S. dollar by 27 percent in nominal terms since the beginning of 2004 (19 percent in real effective terms through April 2006). While the recent dram appreciation has thus far not eroded export competitiveness because it follows considerable exchange rate depreciation between 2000 and 2003 (23 percent in real effective terms) and has occurred in the context of productivity gains, exchange rate developments should be monitored and their economic impact assessed in the coming full PRSP update.

\section{More focus on private sector development issues is needed to strengthen} competitiveness and employment opportunities. The official unemployment rate remains high, particularly among the youth. To generate more jobs and further reduce poverty, it is critical to ensure a satisfactory business environment. The Progress Report now includes a section on the business environment as suggested in the previous JSAN. Periodic business surveys conducted jointly by the World Bank and EBRD every three years show commendable progress in many elements of the business environment in Armenia from 2002 to 2005. However, the latest survey also suggests that the pace of progress has slowed in some important components that affect private sector investment and the efficiency and competitiveness of Armenian firms, including in corporate governance. Improving tax and customs administration (as discussed below) is critical. Strengthening the rule of law and the judicial system is also needed. The staffs encourage the authorities to study further the perceptions of the Armenian business community and publicly discuss the findings of these surveys. The staffs note that the government has adopted a time-bound action plan to further improve the private sector environment, in consultation with private sector representatives, and encourage the government to report on its implementation in the upcoming full PRSP update. Staffs also encourage the authorities to establish plans to strengthen competition in services, particularly in telecommunications and aviation.

7. There is limited discussion in the Progress Report on the financial sector, but the staffs note that recent steps have been taken to improve the lending environment through improving banking supervision, strengthening creditor rights, clarifying procedures for collateral registration and foreclosure, and enforcing contracts. The staffs urge the government to continue to pursue this agenda with vigor, including deepening financial intermediation, strengthening the corporate governance of banks and facilitating the introduction of new financial products such as housing finance. The regulatory framework also needs to be extended to the nonbanking financial sector, including the insurance market. 
Staffs are concerned with the inclusion in the Progress Report of plans to extend subsidized credit to targeted firms following a limited pilot loan guarantee program for SMEs. As the Progress Report notes, most small and medium companies exhibit quite large returns. They therefore do not appear to require subsidized credit to be profitable, while subsidized credit can distort incentives in the financial sector.

\section{B. Fiscal and Budgetary Management}

8. The Progress Report continues to highlight the government's commendable accomplishments in the conduct of fiscal policy. The achievements reported include the use of Medium-Term Expenditure Frameworks (MTEFs) for the past four years, active participation by the line ministries in the design of the MTEFs, and integration of the MTEFs, based on the PRSP process, in the annual budgets of 2004 and 2005. Staffs note that tax revenues rose by 0.3 percent of GDP in 2005 relative to 2004, the largest increase since 1999. However, the tax-to-GDP ratio remains relatively low by regional standards. The Progress Report candidly recognizes that strengthening revenue collection will be an important factor in meeting PRSP social spending goals. Nevertheless, the fiscal situation has remained sound, with consolidated government deficits (including grants) of 1.5 percent of GDP in 2003, 1.6 percent in 2004, and 2.6 percent in 2005 compared with 4 percent in 2001. The Progress Report also presents evidence that expenditures have been switched toward activities with high impacts on poverty reduction.

9. The staffs note that deficiencies in tax and customs administrations continue to be serious impediments to efficient and transparent revenue mobilization and improving the business environment. The staffs urge continued reform of tax and customs administration, as suggested in the previous JSANs, to ensure sustainability of fiscal reforms. The government's medium-term reform program gives priority to large taxpayer unit reform, introduction of self assessment, improvement in tax practices through reduction in arrears, conducting more effective audits, including permitting off-site audits and increasing the time allowed for audits, and the introduction of risk-based systems for audits and VAT refund processing. In customs, there is a need to progressively roll out self-declaration and direct trader input systems, apply selectivity in customs control, improve post-control audit functions, and reduce reliance on the use of reference prices for valuation of imports as against transaction prices. The staffs encourage the government to deepen customs and tax reforms along these lines and reflect on achievements and plans in the full PRSP update.

10. Substantial progress has been made in public expenditure management, but staffs encourage the government to take further steps to improve budget management systems and transparency in public resource management. The authorities have implemented major reforms in public financial management. The latest steps include introducing elements of program budgeting in selected ministries and structuring the budget of pilot ministries around newly defined programs. The staffs commend the government's 
progress in outlining the scope of Public Investment Programs in MTEF documents over the past five years, and for making them available to the general public. The government also notes that it is developing a process of ensuring accountability in non-commercial entities. However, going forward, the government should improve the monitoring system for noncommercial entities (NCEs), expand merit-based pay and performance systems in the public administration system and expand performance-based budgeting practices beyond the pilot ministries. The staffs also suggest that additional improvement is needed in: (i) public procurement, including expanding the use of e-procurement, further standardizing documentation and procedures, and decentralizing responsibility to line Ministries with adequate oversight; (ii) translation of the adopted anti-corruption strategy into specific actions, especially in tax and customs administration reforms; (iii) judicial independence and financing; (iv) development of transparent internal and external audits systems; (v) further upgrading of government accounting and reporting systems; and (vi) expenditure classifications in line with international standards. In addition, the staffs suggest that the government continues increasing priority public investments in key social and infrastructure areas as noted below.

\section{Delivering Social Services}

\section{The Progress Report indicates that the absolute value of social sector} expenditures increased significantly by about 30 percent in real terms between 2002 and 2004, although it has only risen slightly from 7.8 to 8.3 as a percent of GDP and is still below the PRSP target of 9.3 percent of GDP. The staffs recognize the achievements made and agree that setting and meeting ambitious social spending levels should be an important element of the upcoming PRSP Update. Fiduciary oversight, however, remains a concern, particularly against the background of large levels of education and health spending being channeled through noncommercial entities (NCEs) which have weak financial reporting mechanisms and are not yet independently audited. In this respect, staffs encourage the authorities to continue (i) increasing budget allocations for social services in order to ensure salaries and infrastructure are adequate to provide quality services without informal payments, (ii) conducting costing exercises in health and education to ensure they fully reflect service costs, (iii), build capacity within the sectors to utilize and monitor funding wisely, and (iv) improve the efficiency and equity of social spending.

12. In education, the Progress Report indicates that spending rose by 37 percent in 2004, and budget allocations were increased significantly in 2005, which should raise education spending to around 3 percent of GDP, in line with the original PRSP target. This was needed to increase teacher salaries and training, but staffs urge the government to combine this with a revision of the per capita financing formula and an increase in the student teacher ratio from 13 in 2004 to the target of 16 to ensure that resources are focused in an efficient manner. Staffs note the expected decline in student population which will provide an opportunity for further efficiency and quality gains. Staffs also emphasize the importance of 
extending the secondary school term to $12^{\text {th }}$ grade and improving the secondary school curriculum. Staffs appreciate the Progress Report's coverage of actions taken by the government to strengthen pre-school, vocational, and higher education. On higher education, staffs note the need to introduce a student loan scheme to ensure equitable access. Staffs also appreciate the continuing emphasis in the PRSP on upgrading facilities, improving textbooks, and solving heating problems.

13. In the health sector, the Progress Report notes that public resources have considerably increased both in absolute terms and from 1.2 percent of GDP in 2003 to 1.5 percent of GDP in 2005, though still short of the PRSP target of 1.8 percent in 2005 . During this period, increased public funds have been mainly used to finance primary health care services and increase salaries of medical staff. Staffs urge the government to continue to increase health sector funding while working to make the use of funds more efficient via hospital mergers, a continued focus on primary and family health care, and strengthened reimbursement rates for providers to reduce the incidence of informal payments. Staffs recognize that the government has invested in rural health infrastructure, but note that equitable access in rural areas continues to be constrained by lack of trained family practitioners, pharmacies and drugs, as well as by informal payments. Staffs appreciate the continuing effort by the government to reduce maternal and child mortality, but note that sustained efforts are needed to further reduce these indicators to EU levels. Staffs also draw government's attention to the unfinished agenda on communicable diseases, tuberculosis in particular, while praising the recent efforts of the government in adopting a noncommunicable diseases (NCD) prevention and control strategy.

14. On social assistance, the Progress Report notes that the targeted cash family poverty benefit remains a major pillar of the safety net. The government introduced measures aimed at further improving the administration of these benefits, including better monitoring and evaluation, and a more streamlined appeals procedure. The Progress Report also reports a significant increase in the average family benefit, by 26 percent per year in both 2004 and 2005. In social insurance, the government has made satisfactory progress toward introducing individual accounts in the pension systems, improving collection of social insurance contributions, and increasing pensions. The government is encouraged to keep increasing pensions in real terms as they have played an extremely important role in overall poverty reduction, particularly among the elderly, and to ensure that further pension reform is based on the principles of sustainability, reliability, and encouraging savings.

\section{Improving Infrastructure and Modernizing Rural Areas}

\section{The Progress Report documents Armenia's continued good performance in} improving services and accountability in energy and water. Specifically, the staffs note the substantial rise in the budget for road construction and maintenance although it is still less than half of what is needed to bring the network to an adequate level of service; the 
increase in the drinking water tariffs toward cost-recovery levels; and the efforts of the government to diversify the sources of energy supply and increase the utilization of indigenous energy resources. The staffs underline that efforts to protect the most vulnerable from further tariff rises should be through targeted transfers rather than general subsidies. The staffs note the need for more attention to regulatory reforms in the energy and water sectors with a particular focus on service quality and transparency, and suggest that these be discussed in the full PRSP Update. To this end, there is a need to adequately implement the established service quality monitoring system for the electricity sector and to set minimum service quality standards, as well as to continue with the establishment of a service quality monitoring system in the drinking water sector and publish this data. On the latter, staffs note that data are not provided on the average daily duration of water supply, and greater attention should be given to more complete and consistent documentation of Armenia's very real progress in improved water service delivery. Staffs also urge attention to further reducing efficiency losses in the energy and water sectors. Staffs suggest that the PRSP update also discuss needed reform in railways.

16. The PRSP also highlights the importance of strengthening rural development, including rural infrastructure. Based on the diagnostic study for rural infrastructure services, the government has adopted a time-bound action plan of reforms in rural roads, water, energy and telecom sectors emphasizing universal access, equity and clarification of ownership, and private-public partnerships. While some steps have been undertaken toward the implementation of the action plan, staffs note the need to ensure adequate and timely implementation of the plan. Staffs appreciate the candid indication in the PRSP that the issues of agriculture insurance, credit, and the impact of the amalgamation of land should all be addressed in the PRSP update. Staffs also note the importance of strengthening the use of standards in agro-processing. Finally, staffs encourage the government to continue to improve forest management.

\section{Participation, Coordination, And Monitoring}

\section{The staffs commend the authorities for maintaining good consultation and}

participation in PRSP implementation. All major stakeholders in PRSP implementation signed a Partnership Agreement (October, 2004), and formed a new Steering Committee and Working Group (January 2005) to lead and oversee the PRSP implementation process. The PRSP Progress Report also provides details on the discussions held through the Open Forum since its establishment - organizing public discussions in Yerevan and throughout the country on various priority subjects (utility tariffs, human poverty issues, land consolidation, public awareness, the quality and access of education services, etc.) In this way, NGOs not represented in the Steering Committee or the Working Group can continue to participate. Staffs consider it highly inclusive that the Progress Report contains proposals of various NGO groupings on issues for the coming PRSP update. The staffs appreciate all these efforts 
and encourage the government to maintain this emphasis, and deepen confidence for further partnership.

18. Donors have generally integrated their efforts behind the PRSP, although coordination remains largely led by donors. The PRSP Progress Report recognizes the efforts of donor programs to harmonize their activities behind PRSP priorities. All major donors in Armenia (WB, IMF, USAID, EU, GTZ, DFID) have approved their recent country assistance strategies in line with PRSP themes. This year, the U.S. Millennium Challenge Corporation approved funding for priority activities, taking into account the accumulated experience of the PRSP consultation process and poverty reduction priorities. The staffs would like to reiterate the importance of donor coordination activities and urge the government through the PRSP secretariat to take a more active role in this coordination, including strengthening the administrative setup to undertake this task effectively. Staffs suggest strengthening synergies between the PRSP and the European Neighborhood Policy (ENP) action plan. Staffs also note the increasing involvement of private external transfers in poverty reduction, and encourage the government to establish a framework for integrating these funds into the PRSP.

\section{The Progress Report describes good progress on monitoring and evaluation.}

Shortly after approval of the PRSP document, the government created a Monitoring Task Force in November 2003, which approved a set of 177 monitoring indicators. These are largely harmonized with the Millennium Development Goals (MDGs). The staffs commend the authorities for improving poverty measurement, analyses, and findings, and for making data widely available, including through the web (www.prso.am). Nevertheless, the Progress Report is candid that monitoring continues to require attention, and information on some indicators is hard to collect. Staffs note that the government has approved a new decree (July, 2005) on strengthening PRSP implementation reporting. Staffs encourage the government to address these issues further in the PRSP update, to adequately budget for improvements in monitoring through normal public expenditures, and to harmonize PRSP data reporting with budget and MDG reporting.

\section{Conclusions}

20. Armenia has had two very successful years of PRSP implementation in which most of the targets have been met or exceeded and which have been marked by a high level of consultation and participation. The PRSP Progress Report provides a rich set of information on PRSP implementation, and should therefore help donors to assess the progress made by the government in carrying out its poverty reduction strategy. At the same time, there are a few key areas where greater effort will be required, and progress should be measured, over the coming year. These include: (i) strengthening the business environment, particularly in building competition in aviation and telecommunication services, and deepening financial intermediation to build jobs; (ii) continuing to implement tax and customs reform to further 
increase the transparency and level of tax collections; and (iii) deepening reforms in pensions, health and education, to raise the quality of social services. It is recognized that progress in these areas will take time, given that the problems are deep-rooted. It should be mentioned that over the past year significant progress has been made in fiscal reforms and in preparing an action plan for pension reforms.

21. The staffs welcome the authorities' efforts at progressive integration of the PRSP process into the MTEF and budget process, as well as the MDG progress reports. The staffs also note that Armenia has succeeded in making the MTEF process an integral part of the budgeting and planning process. It is encouraging that throughout the last three years, MTEFs have basically reflected PRSP policy priorities. However, as the Progress Report notes, actual developments in Armenia have generally exceeded PRSP projections for 200305 and therefore there is an urgent need to update the macro-fiscal framework projections and outlook for the upcoming period. As the new PRSP update is prepared, any changes to the policy priorities would need to inform the budgetary process through the MTEF. 